\section{"Motor hypothesis" in rats in relation to the cue value and reward value of home cage proximity to the maze}

\author{
MARC BLANCHETEAU* \\ University of Paris, Sorbonne, Paris, France
}

In an unsolvable orientation-problem situation in the alley $\mathrm{T}$-maze, with neither place nor response cues operating, rats develop a persistent "motor hypothesis" without any place orientation. However, in certain conditions, the proximity to the home cage and to the other rats in it may exert a subsidiary reinforcing effect, of a social nature, on motor responses of a given laterality, thus giving the false impression that the cage is a place cue in the spatial orientation of rats looking for food in the maze.

In previous work (Blancheteau, 1969), it was found that rats first orient themselves in an alley $T$-maze by means of a "motor hypothesis" or position habit of a given laterality, equally well in both place and response learning. In the former case, the systematic laterality reduces only when place cues appear to control orientation. We concluded that only the validity of place cues in association with no validity of response cues could reduce the tendency to take a position habit.

To test this assumption, we had to observe whether or not position habits would occur in the absence of such an association; that is to say, with no validity of response cues or of place cues, or in an unsolvable orientation problem. Such a situation is provided for rats by a single alternation learning task with widely distributed trials over time and rather few runs.

\section{EXPERIMENT 1}

Apparatus and Method

The Ss were 13 female albino rats from a Wistar $\mathrm{CF}$ strain, 10 weeks old at the beginning of training, housed in groups of 4 or 5 in their home cages.

The maze was a +-shaped one, with one entrance arm shut at the choice-point level in order to use it as a T-maze. All four arms were alleys 4 in. wide, 6 in. deep, and 20 in. long, covered with Plexiglas. During the experiment, the home cage of the Ss was always put at the same place near the maze, on the east side of the room for five rats and on the west side for the other eight rats.

After some preliminary training to get the rats familiar with the maze, there were six daily sessions of six orientation trials, spaced 15 to $20 \mathrm{~min}$ apart, using the correction method. Food was put in the east or west goalboxes following a single

\footnotetext{
*The author's present address is: Laboratoire de Psychologie experimentale, 28, rue Serpente, Paris $\left(6^{\circ}\right)$, France.
}

alternation schedule. The entrance arm was always the same for each rat: seven Ss were introduced from the north side and six from the south side, this condition being counterbalanced with that of the east or west location of the cage mentioned above.

\section{Results}

There was no learning, the proportion of errors remaining $1 / 2$. Laterality developed up to the criterion of more than 12 consecutive runs in the same direction: $6 \mathrm{Ss}$ consistently took a right turn, 6 Ss a left one, and only $1 \mathrm{~S}$ gave random responses. This finding should confirm the above hypothesis, but a striking observation raises some doubt about its value: laterality was not independent from place cues, because 11 Ss turned towards their home cages. One of them even carried the food to the goalbox near its cage when it had to find it in the opposite one. The 12th $S$ turned at the opposite side; when it was in its cage, it proved to be submissive to other rats and avoided contact with them. The Ss in the maze could not see their cage, but they could hear the many noises made by the companions in it.

\section{Discussion}

One can say that the cage provides the rat in the maze with auditory place cues and thus that the behavior of the $S$ is relevant to a place-learning process. However, since response and place cues are correlated because of the use of one and the same entrance orientation for each $\mathrm{S}$, there is no ground to dismiss the role of response cues. To answer the problem, it is necessary to dissociate these cues by using both entrance orientations for each rat and to look for a "motor" or "place (cage)" hypothesis in Ss' orientation.

\section{EXPERIMENT 2}

Apparatus and Method

In every respect, the conditions were the same as in Experiment 1, except that there were eight trials a day, using both entrance arms for every rat, following a double alternation schedule of the NSSNNSSN type. Twenty-two Ss were used, the home cage being located to the east side of the maze for 11 of them and to the west side for the 11 others.

\section{Results}

Again there was no learning, the proportion of errors remaining at the $50 \%$ level. Lateralization also was observed in 21 Ss: 11 took consistently a left turn and 10 a right one. Thus, cage location appears to play no role at all: the orientation of rats was a typical "motor hy pothesis," not a "place" one. Moreover, in a 7 th session, we reversed the location of the cages, without any effect on orientation.

GENERAL DISCUSSION

Experiment 2 supports our assumption on the role played by the "motor hypothesis" in first orientation behavior; however, the coincidence of chosen laterality and cage location in Experiment 1 needs to be explained.

Auditory stimuli from the cage are not place cues or CS for food US, but we can assume that they possess a social US value, thus acting as subsidiary reinforcers of the motor responses leading the rat to the vicinity of its companions. The motivational value and fear-reducing effect of such a social proximity was recently demonstrated by Davitz \& Mason (1955), Latané \& Glass (1968), and Baum (1969). In Experiment 1, food reinforcement ( $R f$ ) of right or left turns is partial (50\% ratio) because of the single alternation design, whereas social $\mathrm{Rf}$ is consistent, due to permanence of cage location: a given response can lead consistentlv to case vicinity, but not to food, so its $\mathrm{Rf}$ becomes of a social nature. Such effects of subsidiary but consistent $\mathrm{Rf}$ are assumed by Lawrence \& Festinger (1962) to explain rat behavior in partial food Rf experiments. Thus, development of laterality in our Ss depends on the location of its social reinforcer.

In expenment 2 , on the contrary, social $R f$ is as partial as the food $R f$ is with regard to a given response and therefore it cannot act as a subsidiary reward for it; thus, the position habit develops free of any place contingency.

To sum up, the proximity of companions can give rise to possible artifacts in orientation experiments, with rats in mazes (Ritchie, 1947) as well as with birds in experimental ethology (Perdeck, 1963), unless this variable is properly controlled.

\section{REFERENCES}

BAUM, M. Extinction of an avoidance response motivated by intense fear: 
Social facilitation of the action of response prevention (flooding) in rats. Behaviour Research \& Therapy, 1969, 7 , 57-62.

BLANCHETEAU, M. L'orientation spatiale chez l'animal, ses indices et ses reperes. Monographies Francaises de Psychologie, Paris: Centre National de la Recherche Scientifique, 1969.

DAVITZ, J. R., \& MASUN, D. J. Socially facilitated reduction of a fear response in rats. Journal of Comparative \& Physiological Psychology, 1955, 48, 149-151.

LATANE, B., \& GLASS, D. C. Social and non-social attraction in rats. Journal of Personality \& Social Psychology, 1968, 9. $142-146$.

LAWRENCE, D. H., \& FESTINGER, L. Deterrents and reinforcement: The psychology of insufficient reward. Stanford, Calif: Stanford University
Press, 1962

PERDECK, A. C. Does navigation without visual clues exist in robins? Ardea, 1963, 51, 91-104.

RITCHIE, B. F. Studies in spatial learning: 11I. Two paths to the same location and two paths to two different locations. Journal of Experimental Psychology, $1947,37,25-38$.

\section{CURRENT LITERATURE ON MAZE AND RUNWAY BEHAVIOR}

BARRETT, R, J. (Psychology Research Laboratories, Veterans Administration Hospital, Nashville, Tenn. 37203), HUGHES, R. A., \& RAY, O. S. ECS disruption of time-dependent processes in discriminated-avoidance conditioning in rats: Incubation or consolidation? Journal of Comparative and Physiological Psychology, 1971, 74, 319-324.

BELL, R. W. (Northern Ilinois University, DeKalb, Ill. 60115), MILLER, C. E., ORDY, J. M., \& ROLSTEN, C. Effects of population density and living space upon neuroanatomy, neurochemistry, and behavior in the C57B1/10 mouse. Journal of Comparative and Physiological Psychology, 1971, 75, 258-263.

BRUNING, J. L. (Ohio University, Athens, Ohio 45701), SCHMECK, R. R., \& SILVER, A. I. Frustration, competing resonses, and error making. Psychonomic Science, $1971,22,47-48$.

CAMPBELL, E. M., \& MEYER, P. A. (University of South Dakota, Vermillion, S. Dak. 57069). Effects of daily reward sequence on simultaneous and successive negative contrast in rats. Journal of Comparative and Physiological Psychology, 1971, 74, 434-440.

CAMPBELL, P. E. (Southern Methodist University, Dallas, Tex. 75222), CRUMBAUGH, C. M., RHODUS, D. M., \& KNOUSE, S. B. Magnitude of partial reward and amount of training in the rat: An hypothesis of sequential effects. Journal of Comparative and Physiological Psychology, 1971, 75, 120-128.

DI LOLLO, V. (University of Western Australia, Nedlands, Western Australia 6009), \& ALLISON, J. Relative magnitude of end-box reward: Effects upon performance throughout the double runway. Journal of Experimental Psychology, 1971, 87, 248-254.

DUNCAN, N. C., GROSSEN, N. E., \& HUNT, E. B. (University of Washington, Seattle, Wash. 98105). Apparent memory differences in inbred mice produced by differential reaction to stress. Journal of Comparative and Physiological Psychology, 1971, 74, 383-389.

JENSEN, P. K. (Drew University, Madison, N.J. 07940). Role of blind alleys in latent learning. Journal of Experimental Psychology, 1971, 88, 133-136.

KNOUSE, S. B., \& CAMPBELL, P. E. (Southerm Methodist University, Dallas, Tex. 75222). Partially delayed reward in the rat: $A$ parametric study of delay duration. Journal of Comparative and Physiological Psychology, 1971, 75, 116-119.

MORLOCK, G. W., McCORMICK, C. E., \& MEYER, M. E. (Western Washington State College, Bellingham, Wash. 98225). The effect of a stranger's presence on the exploratory behavior of rats. Psychonomic Science, 1971, 22,
3-4.

PORTER, J. J. (University of Wisconsin, Milwaukee, Wis. 53201), DAVIS, R. C., \& MADISON, H. L. Instrumental escape behavior with extended training. Behavior Research $M$ e thods \& Instrumentation, 1971, 3, 127-129. RASHOTTE, M. E. (Florida State University, Tallahassee, Fla. 32306), \& AMSEL, A. Performance of rats in a runway under three concurrent conditions of reinforcement. Psychonomic Science, 1971, 22, 21-23.

SGRO, J. A. (Virginia Polytechnic Institute, Blacksburg, Va. 24061), SHOWALTER, J. R., \& COHN, N. H. Frustration effect following training with continuous and partial delay of reward. Journal of Experimental Psychology, 1971, 87, 320-325.

THOMAS, G. J. (Center for Brain Research, University of Rochester, Rochester, N.Y. 14627). Maze retention by rats with hippocampal lesions and with fornicotomies. Journal of Comparative and Physiological Psychology, 1971, 75, 41-49.

WEINSTOCK, R. B. (Mary Washington College of the University of Virginia, Fredericksburg, Va. 22401). Preacquisition exploration of the runway in the determination of contrast effects in the rat. Journal of Comparative and Physiological Psychology, 1971, 75, 107-115. 